\title{
The episodic nature of involuntary autobiographical memories
}

\author{
DORTHE BERNTSEN and NICOLINE MARIE HALL \\ University of Aarhus, Aarhus, Denmark
}

\begin{abstract}
Involuntary autobiographical memories are conscious and unintended recollections of personal experiences. In Study 1, involuntary memories were compared with voluntary word-cued memories, both retrieved in naturalistic settings via a self-paced procedure. The involuntary memories more frequently referred to specific episodes, came with more physical reaction, had more impact on mood, and dealt with more unusual and less positive events. Study 2 demonstrated that these differences were not due to differences between verbal and nonverbal cues, by using Francis Galton's "memory walk" as a nonverbal method to cue voluntary memories. In both studies, systematic differences were found between specific and nonspecific memories. The findings show that the way autobiographical memories are sampled greatly affects the findings and that involuntary retrieval more often provides access to memories of specific episodes and associated emotional states.
\end{abstract}

I was waiting at the bus-stop, thinking that it was a bit of a gloomy place to be standing all by myself. Some strange sounds were coming from the neighboring factory. In the street, the cars are passing me. A car with unusually sharp headlights is approaching me. I suddenly remember my younger brother's eight years birthday. He got a toy robot that could shine with its eyes and was able to walk.

To have an involuntary autobiographical memory is to become aware of a past experience with no preceding conscious attempt at retrieval, as is illustrated by the example above. Such memories are frequent in everyday life. Diary studies (from which the example above derives) indicate that they occur several times a day for undergraduates (Berntsen, 1996, 1999, 2001). A survey study of a large stratified sample of the Danish population showed that involuntary autobiographical memories were well known, and $58 \%$ of the respondents said they were able to remember the last time they had had an involuntary memory (Berntsen \& Rubin, 2002; see also Brewin, Christodoulides, \& Hutchinson, 1996).

Although involuntary conscious memories are generally recognized as important for our understanding of memory (see, e.g., Mandler, 1989, 1994; Neisser, 1982b), were mentioned as one of three basic manifestations of memory by Ebbinghaus (1885/1964), and have been observed in clinical settings in relation to a wide range of disturbances (e.g., Horowitz, 1975; Reynolds \& Brewin, 1999; Stevenson \& Cook, 1995), experimental psycholo-

This work was supported by a grant from the Danish Research Council for the Humanities. Thanks to Kim Berg Johannesen and Sus Desiree for their assistance with Study 2. Thanks to David Gallo, Reza Habib, Peter Krøjgaard, David C. Rubin, Dorthe Thomsen, and an anonymous reviewer for helpful comments. Correspondence concerning this article should be addressed to D. Berntsen, Department of Psychology, University of Aarhus, Nobelparken, Jens Chr. Skousvej 4, 8000 Aarhus C., Denmark (e-mail: dorthe@psy.au.dk). gists have tended to neglect them. For example, in his classic work, Miller (1962/1974) opens his chapter on memory by quoting Proust's (1932-1938) example of a longforgotten childhood memory triggered by the taste of a Madeleine cookie, and Miller adds the following: "A prudent psychologist might well decide to leave such fragile flowers to Proust and his fellow artists. A scientist would do better to study the workaday memory that guides our plans, feeds our inferences, answers promptly when it is called and stands still long enough to be measured" (p. 181). Most psychologists appear to have followed Miller's advice. Systematic studies on involuntary conscious memories have so far been scattered. Outside of autobiographical memory, two distinct areas of laboratory research have addressed involuntary conscious memories, although not necessarily as a key issue and with only a few experiments. One area is research on implicit memory (see Kinoshita, 2001, for a review); the other is clinical studies of intrusive memories and flashbacks following traumas (e.g., Horowitz, 1975). In addition to research in these areas, a few studies of involuntary conscious memories exist in other areas, such as studies on involuntary memories during the learning of a new cognitive skill (e.g., Ross, 1984) and in relation to the reception of fictional literature (Larsen \& Seilman, 1988; see Berntsen, 1996, 1998, and Kvavilashvili \& Mandler, 2004, for more reviews). We will start with a review of the empirical work on involuntary autobiographical memory, to delineate the central questions for the present studies. In our General Discussion section, we will discuss how our findings relate to research on involuntary conscious memories in other areas.

\section{Studies on Involuntary Autobiographical Memories}

A structured diary method is a useful way to obtain information about involuntary autobiographical memories 
in everyday life, because it allows records to be taken immediately and, thus, relies little on retrospection, which can contaminate the self-reports with guessing and personal beliefs (Ericsson \& Simon, 1980; Nisbett \& Wilson, 1977). To date, data from only four diary studies exist in the literature on involuntary autobiographical memories. Berntsen (1996) conducted an exploratory investigation of involuntary autobiographical memories among undergraduates. Berntsen (2001) reported results from two diary studies. One involved undergraduates with a posttraumatic stress disorder (PTSD) symptom profile (Study 2). Another (Study 4) involved undergraduates who had encountered a peak experience - that is, an unusually happy event with positive long-term consequences for the well-being of the person (Maslow, 1959). Recently, Kvavilashvili and Mandler (2004) compared retrieval mechanisms for involuntary autobiographical memories versus involuntary semantic memories (i.e., single words and images that are devoid of reference to a specific episodic context). Because Berntsen (2001) was especially interested in the effects of traumas on the frequency and phenomenological quality of involuntary autobiographical memories, she did not report findings related to retrieval mechanisms. In the following, reanalyses of her data on retrieval will be presented together with results from Berntsen (1996) and Kvavilashvili and Mandler.

Berntsen $(1996,2001)$ asked her participants to report any salient commonalities that they perceived between the memory and the retrieval situation and to classify these as external (present in the physical surroundings) or internal (present only in thoughts) or mixed (a combination of external and internal features). An overview of the results is presented in Table 1. As it appears, specific cues could be identified for the great majority of memories in all three studies, and these cues were most frequently features of the external surroundings. Similarly, Kvavilashvili and Mandler (2004) found that specific triggers of involuntary autobiographical memories could be found for $80 \%$ of the memories. In addition to distinctive cues, Berntsen (1996) found a mood congruence effect in terms of a significant correlation between mood prior to retrieval and the emotional content of the memory. Reanalyses of the data from Berntsen (2001) also showed weak, but significant, correlations between mood and the emotional content of the memories $[r(597)=$ $.16, p<.001$, and $r(690)=.29, p<.0001$, for Study 2 and Study 4, respectively]. Berntsen (1998) showed that involuntary autobiographical memories generally come to mind when attention is nonfocused (such as during relaxation, routine tasks, or moments of distraction). Kvavi-

\section{Table 1}

Percentages of Involuntary Memories With External, Internal, Mixed, and No Identifiable Cues in Previous Studies

\begin{tabular}{lccccc}
\hline \multicolumn{1}{c}{ Study } & $N$ & External & Internal & Mixed & No Cues \\
\hline Berntsen (1996) & 700 & 37 & 24 & 31 & 8 \\
Berntsen (2001, Study 2) & 600 & 44 & 31 & 15 & 11 \\
Berntsen (2001, Study 4) & 700 & 43 & 20 & 26 & 10 \\
\hline
\end{tabular}

lashvili and Mandler replicated this finding for both involuntary autobiographical and involuntary semantic memories.

\section{Emotional Content}

Following Horowitz (1975), involuntary autobiographical memories were long thought to deal preferentially with negative or troublesome experiences, such as memories referring to unresolved personal problems (Klos \& Singer, 1981) or traumas. Even though involuntary (often called intrusive) memories of traumas are still a signpost of PTSD (American Psychiatric Association, 1994; Harber \& Pennebaker, 1992), it is now well documented that involuntary memories are common in everyday life and deal with a broad range of personal experiences associated with positive, negative, and neutral emotions (Berntsen, 1996, 2001, 2002; Berntsen \& Rubin, 2002; Brewin, Christodoulides, \& Hutchinson, 1996).

Although memories of traumatic events seem to be more prone to arise involuntarily, as compared with memories of peak experiences (Berntsen, 2001), involuntary autobiographical memories are most frequently positive, consistent with what has been found for autobiographical memories in general (Thompson, Skowronski, Larsen, \& Betz, 1996). Berntsen (1996) found a dominance of positive memories in her diary study, in that $49 \%$ were rated positive, $19 \%$ were negative, and $32 \%$ were neutral or mixed. Berntsen and Rubin (2002) got similar results when they asked a representative sample of the Danish population to rate their most recent involuntary memory as positive $(55 \%)$, negative $(21 \%)$, or mixed $(24 \%)$. In Berntsen's (2001) study of undergraduates with a PTSD symptom profile, only $5 \%$ of the involuntary memories referred directly to the reported traumas. The mean rating of the emotional content for the remaining $95 \%$ of the memories was slightly positive $(0.09$ on a -2 to +2 scale for emotion). Brewin, Christodoulides, and Hutchinson (1996) obtained an equal number of positive and negative involuntary memories when they asked their participants for "their five most frequent intrusive memories from the past two weeks" (p. 108). The relatively large frequency of negative memories in this study may reflect the fact that participants were told, as part of the instructions, that intrusive memories "may be difficult to control, hard to mention or even embarrassing" (p. 108).

\section{Comparative Studies of Involuntary and Voluntary Autobiographical Memories}

As has been argued by Berntsen (1998), one consequence of the general neglect of involuntary autobiographical memories is that theories of autobiographical memory have been based on data that derive almost exclusively from studies of voluntary autobiographical memories. To the extent that involuntary and voluntary autobiographical memories differ, studies focusing on just one of the two types of memories will be biased. For example, when asked to (deliberately) retrieve memories for specific events, people often - counter to the instructions givenrespond with descriptions of higher order knowledge, 
such as schematic representations of recurrent personal events of a particular kind (often called summarized events; Barsalou, 1988), overgeneral events (Williams, 1996), or repisodes (Neisser, 1982a). This effect is even more pronounced in people with depression (Williams, 1996) and PTSD (McNally, Lasko, Macklin, \& Pitman, 1995; see McNally, 2003, for a review). On the basis of such findings, it has been claimed that generic autobiographical memory is generally more accessible than memories for specific episodes and that the latter are constructed from higher order schematic knowledge, rather than depending on the reactivation of specific traces (e.g., Barclay, 1993; Conway \& Pleydell-Pearce, 2000; Neisser, 1982a).

However, findings from studies on involuntary autobiographical memories appear to contradict the idea that memories of specific episodes are generally less accessible than generic memories. Berntsen (1998) compared involuntary memories with memories retrieved in response to cue words. The word cues were generated so as to be comparable to the cues recorded in Berntsen's (1996) diary study of involuntary autobiographical memories. The most important difference was a significant dominance of specific episodes, as opposed to summarized events, among the involuntary memories $(89 \%)$, but not among the word-cued memories (63\%). Reanalyses of the two diary studies reported by Berntsen (2001) showed a similar overweighting of specific episodes among the involuntary memories, in that $80 \%$ and $81 \%$, respectively, referred to specific events. The dominance of specific episodes found in involuntary retrieval (even when nonspecific memories were allowed) indicates that frequencies of specific and nonspecific episodic memories vary with the memory task and that involuntary retrieval is more effective than voluntary goal-directed retrieval in accessing memories of specific episodes, consistent with Berntsen (1998) and Moscovitch (1994, 1995a, 1995b).

However, to date, only one comparative study of involuntary and voluntary memories exists in the literature, and possible confounds may have biased Berntsen's (1998) results. The involuntary memories were retrieved in a naturalistic context via a self-paced procedure, whereas the voluntary memories were retrieved in a laboratory via a non-self-paced word-cuing technique. It is not clear whether these differences in experimental conditions are responsible for the results, or whether involuntary and voluntary retrieval also access phenomenologically different memories when such possible confounds are eliminated. Among other things, Study 1 was intended to clarify this question.

\section{Phenomenological Qualities of Autobiographical Memories}

Autobiographical memory involves a conscious reexperiencing of the original event, according to most definitions. This aspect of remembering (often called reliving) is concerned with the quality of appearance of the remembered material, rather than with the remembered material itself and its correspondence with the past. Reliving qualities are recognized as important for distinguishing autobiographical memories from mere autobiographical facts. Brewer (1996) offers a thorough overview of the psychological and philosophical literature and summarizes as follows: "A personal memory is a recollection of a particular episode from an individual's past. It frequently appears to be a 'reliving' of the individual phenomenological experience during that earlier moment. The contents almost always include reports of visual imagery with less frequent occurrences of other forms of imagery ..." (p. 34). In addition, the memory is accompanied by a belief that the event was personally experienced by the self, according to Brewer (for similar descriptions, see Conway, 1992; Larsen, 1998; Rubin, Burt, \& Fifield, 2003; Rubin, Schrauf, \& Greenberg, 2003). This description of autobiographical memory can be seen as closely related to Tulving's notion of episodic memory (Tulving, 1985, 1993; Wheeler, Stuss, \& Tulving, 1997). A defining feature for episodic memory is a state of mentally traveling through time to reexperience the remembered event. As was stated by Wheeler et al., "We propose that the ability to mentally travel through time is an expression of the episodic memory system of the brain and that this ability is not shared by other systems of memory" (p. 331). This form of memory awareness is called autonoetic awareness and is assumed to be positively related to the recall of specific episodes - that is, memories of unique events referring to a specific time and place in the past (Tulving, 1985, 1993).

So far, no studies have compared the reliving qualities of involuntary and voluntary autobiographical memories. However, observations from fictional literature and autobiographies indicate that involuntary memories come with extraordinarily high levels of sensory and emotional reliving. The Russian novelist Esther Salaman (1982) gave examples of involuntary memories from autobiographical literature and argued that "such memory . . . overthrows the order of time and makes one live in another period" (p. 53). Marcel Proust accords: "The 'I' that I once was, and who had disappeared for so long, was now so close to me ... I was nobody but that being" (quoted from Slater, 1991, p. 8). The phenomenological experiences described by these authors can be summarized as an experience of "traveling back in time"-and thus, as a key feature of autonoetic awareness (Wheeler et al., 1997) or reliving (Brewer, 1996). Furthermore, Berntsen $(1996,2001)$ showed that involuntary memories influence the mood of the rememberer to be consistent with the emotional content of the memory and often come with a distinctive bodily reaction, such as palpitation. This indicates that involuntary autobiographical memories involve reliving of the emotion associated with the memory. This can also be seen as consistent with LeDoux's (1996) assumption that reactivations of earlier emotional states to a large extent depend on nonvolitional associative processes. However, whether involuntary memories involve more reliving of emotion than does a comparative sample of voluntary memories remains to be examined and is one of the key issues for the present work. 
Taken together with Berntsen's (1998) findings on the dominance of specific episodes in involuntary autobiographical memories, anecdotal observations on reliving in involuntary memories can be seen to indicate that involuntary autobiographical memories access specific episodes to a greater extent than does voluntary goaldirected retrieval and that they, therefore, are associated with more autonoetic awareness. This is consistent with Moscovitch (1994, 1995a, 1995b), who argued that the medial temporal lobes/hippocampal complex and related limbic structures are responsible for the encoding and reactivation of memories of specific episodes, including the element of consciousness. He distinguished associative retrieval (when the cue alone is sufficient for retrieval) from strategic retrieval (when the cue only provides the starting point for a more deliberate memory search) and argued that reactivation of memories of episodes depends on associative retrieval. Memory traces of episodes are activated via an ecphoric process, which is an automatic interaction between a cue and a memory trace. The resulting retrieval process is described as modular-that is, "rapid, obligatory, informationally incapsulated and cognitively impenetrable" (Moscovitch, 1994, p. 277), consistent with Fodor's (1983) conception of modularity. Strategic retrieval, on the other hand, is dependent on structures in the prefrontal lobes, according to Moscovitch. Findings from brain-imaging studies support the distinction between hippocampal activations related to successful conscious retrieval and prefrontal activations related to intentional retrieval efforts (Rugg, Fletcher, Frith, Frackowiak, \& Dolan, 1997; Schacter \& Buckner, 1998).

In order to investigate whether involuntary autobiographical memories are associated with more subjective reliving than are voluntary autobiographical memories, and to investigate whether the amount of reliving is related to the specificity of the memories, Study 1 offers a systematic comparison between the reliving qualities associated with involuntary and voluntary autobiographical memories and the reliving qualities associated with episodic and nonepisodic memories in the two conditions.

\section{STUDY 1}

In Study 1, the level of specificity and several phenomenological variables for involuntary and voluntary autobiographical memories were compared in order to test the hypotheses that involuntary memories are more frequently about specific episodes and involve more reliving of the original experience. The measures of reliving included here deal with self-reported ratings of vividness, emotional impact, remember/know judgment of the emotions associated with the event, and physical reaction to the memory, to measure the extent to which the rememberer feels that he or she is traveling back in time to reexperience the event (Wheeler et al., 1997). Berntsen's (1998) study involved no measures of reliving qualities and fewer ratings of event characteristics than in the present study. In addition, Study 1 has important methodological advantages over the study reported by Berntsen (1998), in that both the involuntary and the voluntary memory tasks were carried out in the person's natural environment and via a self-paced procedure.

\section{Method}

\section{Participants}

Nineteen Danish undergraduates (10 females, 9 males; mean age, 23.5 years; range, 19-30) participated. Each participant was paid 1,000 Danish kr. (around \$150).

\section{Design, Procedure, and Materials}

The task of each participant was to record 40 involuntary memories and 40 word-cued memories during an open-ended time period, with a maximum of two memories of each kind per day. This formulation of the task was intended to prevent a feeling of time pressure by the participants, to ensure that the involuntary memories recorded in the study really did come unbidden, rather than being provoked by task demands. Each time an involuntary memory was recorded, a word-cued memory had to be recorded next.

The two-step recording procedure introduced by Berntsen (1996) was followed for the recording of the involuntary memories. A third step was added here to enable the recording of a word-cued memory for each involuntary memory. First, immediately after an involuntary memory had occurred, the participant recorded keyword phrases and ratings in response to a set of questions listed in a small notebook, which he or she was instructed to carry at all times. The purpose of this step was to provide an immediate record of the memory and its retrieval context and, thereby, prevent the participant from relying on retrospection and inferences when filling in a more comprehensive questionnaire later on (cf. Ericsson \& Simon, 1980; Nisbett \& Wilson, 1977). The recording in the notebook took little time and, thus, interfered little with the participant's everyday activities. Second, at a self-chosen time later the same day, the participant answered a more extensive questionnaire about each involuntary memory, assisted by the keyword phrases and ratings in the notebook. Each question in the notebook corresponded to a question on the questionnaire. Third, when the involuntary memory questionnaire was completed, the participant removed an adhesive label on the questionnaire, revealing a word cue. The participant recorded a memory in response to the word cue and answered a subset of the same questions that were answered for the involuntary memory.

The questions answered for each involuntary memory are presented in Appendix A. The questions for which the participants were asked to provide keyword phrases or ratings in the notebook are marked with an asterisk. The subset of questions that was also answered for the word-cued memories were Questions 7 and 10-18. The 40 cue words for the word-cued memories were a subset of the 50 cue words used by Berntsen (1998). All the cue words in the present study consisted of one word. The distribution across thematic categories matched the distribution of the seven most frequently reported cue categories in Berntsen's (1996) diary study of involuntary memories. Appendix B shows an English translation of the 40 Danish cue words, classified according to the seven cue categories.

Both verbal and written instructions were given. The verbal instructions were given at a meeting at which only the second author and the participant were present. The verbal instructions clarified and elaborated the written ones, which were given to the participant at the same meeting. An involuntary memory was defined as a memory about a past event that has been brought to consciousness with no preceding conscious attempts at retrieval. Involuntary memories could be cued by the present surroundings or aspects of current thought, as long as the association in question had been established without voluntary attempts. It was stressed that involuntary memories could deal with all kinds of personal experiences, pleasant as well as unpleasant events, recent as well as remote events, and so forth. Also, the difference between specific episodes 
and summarized events (Barsalou, 1988) was carefully explained and exemplified. The participants were informed that both types of memories could be recorded for the involuntary, as well as for the word-cued, memories. A specific episode was defined as an event that could be allocated a specific time and place in the past and that had lasted less than a day-such as, "yesterday when I went shopping in $x$ store" or "the day we saw a fox in the wood." A summarized event was described as a generalized representation that summarized the properties of many similar occasions - such as, "going shopping in $x$ store" or "walking in the wood." The contradistinction between specific episodes and summarized events was used because it appears to be the most common way of distinguishing specific and generic forms of autobiographical memory (e.g., Neisser, 1982a; Nelson, 1993).

It was explained and demonstrated to the participants that the content and order of the questions for the word-cued memories were exactly similar to the content and order of a subset of questions for the involuntary memories. The experimenter used emotionally neutral examples as illustrations during all of the instructions.

After the diary study, each participant was interviewed individually. At this meeting, the interviewer asked the participant for feedback on the procedure and content of the study, especially whether the participant had found parts of it difficult to accomplish. Also, the participant was asked to clarify any responses on his or her memory questionnaires that possibly appeared ambiguous to the experimenter.

A contract informing the participant of his or her ethical rights was signed by both the participant and the experimenter at the beginning of the diary study (for details, see Berntsen, 1996, 2001). Among other things, the participant was informed that it was legitimate to skip a record if it appeared too intimate and embarrassing. This rule was made because there was no way of preventing the participants from excluding records. Consequently, the most sensible thing to do was to formulate the task so that this was legitimate, because this would allow the experimenter to ask, subsequent to recording, whether or not the participant had used the right to censor and a fairly honest answer could be expected. When the participants were questioned during the interview subsequent to recording, all the participants, with the exception of one, either had not censored at all or had censored only 1-3 involuntary or word-cued memories, because they had found the content too private or intimate to be reported. One person stated that she had censored 5-10 memories. (The responses of this participant did not deviate from the rest of the participants, for which reason the data deriving from this participant were not treated separately.) In short, given that the participants were to record a total of 80 memories, they appear to have censored very little.

\section{Results}

The first part of the Results section will deal with retrieval mechanisms for involuntary memories. The second part will deal with differences between the involuntary and the word-cued memories with respect to frequencies of specific events, reliving qualities, and characteristics of the remembered events.

\section{Retrieval Mechanisms for Involuntary Memories}

To avoid contaminating the data with guesses or personal inferences, we did not ask the participants what had triggered their memories (Ericsson \& Simon, 1980). We simply asked them to report any salient commonality that they perceived between the content of the memory and the context for its retrieval. In the following, such commonalities will be labeled cues for the sake of simplicity. No cues were identified for 105 memories (13.9\%). One cue category (e.g., the same place) was identified in 465 cases $(61.2 \%)$. Combinations of two or more cue categories (e.g., the same place and the same activity) were found in 190 cases $(25.0 \%)$. All the participants reported at least 3 memories triggered by compound cues; none reported more than 20 . Table 2 shows the frequencies by which each cue category was identified as a salient commonality between a memory and its retrieval context, alone or combined with other cue categories. The two most frequently identified categories were theme (e.g., the memory was seen to exemplify the theme of a conversation) and object (e.g., the same specific object was present in both the memory and the retrieval contexts). But also person, location, activity, and sensory experience were frequently mentioned cue categories. Emotional states (feelings) were seldom reported alone, but sometimes together with other cue categories. The distribution of cue categories in Table 2 suggests a dominance of external perceptual cues (such as particular objects, persons, or locations) relative to internal conceptual cues (such as themes, life themes, or feelings). This suggestion is confirmed by the participants' scoring of cues as external, internal, and mixed. Of the 655 cases for which a cue was identified, $346(53 \%)$ were classified as perceived in the external environment, $177(27 \%)$ as internal, and $130(20 \%)$ as mixed $\left[\chi^{2}(2)=118.4, p<\right.$ $.0001]$. The difference between the frequencies of external and internal cues (when mixed cues were excluded from the analysis) was significant $\left[\chi^{2}(1)=54.6, p<.0001\right]$.

Table 2

Frequencies by Which Each Cue Category Was Identified as a Salient Commonality Between a Memory and Its Retrieval Context, Alone (Single) or Combined With Other Cue Categories

\begin{tabular}{|c|c|c|c|c|c|c|}
\hline \multirow[b]{2}{*}{ Cue Category } & \multicolumn{2}{|c|}{ Single } & \multicolumn{2}{|c|}{ Combined } & \multicolumn{2}{|c|}{ Total } \\
\hline & No. & Percentage & No. & Percentage & No. & Percentage \\
\hline Theme & 105 & 23.5 & 53 & 12.5 & 158 & 18.1 \\
\hline Object & 101 & 22.6 & 47 & 11.1 & 148 & 17.0 \\
\hline Person & 51 & 11.4 & 60 & 14.1 & 111 & 12.7 \\
\hline Location & 32 & 7.2 & 60 & 14.1 & 92 & 10.6 \\
\hline Activity & 39 & 8.7 & 52 & 12.2 & 91 & 10.4 \\
\hline Sensory experience & 32 & 7.2 & 54 & 12.7 & 86 & 9.9 \\
\hline Feeling & 7 & 1.7 & 52 & 12.2 & 59 & 6.8 \\
\hline Wording & 17 & 3.8 & 24 & 5.6 & 41 & 4.7 \\
\hline Life theme & 18 & 4.0 & 17 & 4.0 & 35 & 4.0 \\
\hline Other & 44 & 9.9 & 6 & 1.4 & 50 & 5.7 \\
\hline
\end{tabular}


Moreover, the overweighting of external cues, relative to internal ones, was consistent across the 19 participants, in that only 4 participants reported more internal than external cues ( $p<.05$ by a binomial test).

In addition to the effect of concrete cues, a mood congruence effect was found, in that ratings of current mood correlated significantly with ratings of the emotional content of the involuntary memory $[r(736)=.23, p<.0001]$. To control for the fact that the 736 cases were clustered around 19 participants, a multiple regressions analysis was conducted with dummy-coded variables, to control for variance among participants. The dependent variable was emotion in the memory and the independent variables were mood at retrieval plus 18 dummy-coded variables to partial out participant variance. The dummy-coded participant variables are included in the regression analyses as independent variables distinguishing that part of the total variance that comes from each participant. With this method, each memory can be legitimately treated as an independent observation (Cohen \& Cohen, 1983; Thompson et al., 1996). This analysis confirmed the mood congruence effect $[t(716), \beta=.20, p<.0001]$.

The findings on the retrieval of involuntary memories replicated earlier work: The great majority of the involuntary memories had identifiable cues. These cues most frequently referred to concrete perceptual features of the external world, rather than to thoughts and emotions. Also, consistent with earlier studies, a mood congruence effect was found, in that current mood (at retrieval) correlated with the emotional content of the involuntary memories, indicating that mood may have functioned as part of a compound cue that may not have been reported or realized by the participants.

\section{The Phenomenology of Involuntary and Word-Cued Memories}

In agreement with previous work, a greater proportion of the involuntary memories referred to specific episodes. Almost twice as many voluntary as involuntary memories referred to nonspecific events (cf. Table 3 ). In agreement with anecdotal observations, involuntary memories involved more reliving of the memory, in that a greater proportion of involuntary memories was accompanied by a physical reaction and had a perceivable impact on the mood of the person. Furthermore, involuntary memories were rated as dealing with more unusual and less emotionally positive events. To control for the fact that the data were clustered around 19 participants, the analyses reported in Table 3 were based on means calculated within each participant. This reduces the power of our analyses considerably, so that we are able to see only large differences, which is likely to explain why no significant difference was obtained between remember/know assessments of emotions in the two conditions, although a trend was found $(p=.17)$. Using a less conservative technique, an analysis of variance (ANOVA) was conducted based on the individual memory records, with remember/ know judgment for involuntary and word-cued memories
Table 3

Mean Scores of Involuntary and Word-Cued Memories

\begin{tabular}{lcccccc}
\hline & \multicolumn{3}{c}{ Involuntary } & & \multicolumn{3}{c}{ Word Cued } & \\
\cline { 2 - 3 } & $M$ & $S D$ & & $M$ & $S D$ & $t(18)$ \\
\hline Specific episodes & 0.83 & 0.10 & & 0.69 & 0.14 & $3.81 \dagger$ \\
Physical reaction & 0.32 & 0.19 & & 0.23 & 0.16 & $2.58^{*}$ \\
Mood impact & 0.48 & 0.21 & & 0.36 & 0.20 & $4.25 \ddagger$ \\
Mood change (+/-) & 0.11 & 0.20 & & 0.14 & 0.15 & 0.95 \\
Remember/know & 0.50 & 0.21 & & 0.45 & 0.23 & 1.34 \\
Vividness & 3.16 & 0.44 & & 3.09 & 0.65 & 0.58 \\
Rehearsal & 2.30 & 0.57 & & 2.41 & 0.54 & 1.04 \\
Unusualness & 3.38 & 0.46 & & 2.97 & 0.38 & $4.02 \ddagger$ \\
Emotion & 0.24 & 0.31 & 0.37 & 0.25 & $2.37^{*}$ \\
Intensity & 3.19 & 0.45 & 3.10 & 0.49 & 1.16 \\
Importance & 2.39 & 0.55 & 2.51 & 0.50 & 1.31 \\
Years old & 3.47 & 2.38 & 3.91 & 1.55 & 0.87 \\
\hline
\end{tabular}

${ }^{*} p<.05 . \quad \dagger p<.01 . \quad \ddagger p<.001$.

as a repeated measures factor and the 19 participants treated as a grouping variable (Wright, 1998). Consistent with our expectation, a significant main effect was found for remember/know estimates for the two classes of memories $\left[F(1)=5.97, M S_{\mathrm{e}}=0.20, p=.01\right]$.

The observed differences in Table 3 between involuntary and word-cued memories on physical reaction, mood impact, and unusualness might derive simply from the higher frequency of specific episodes among the involuntary memories. First, the extent to which memories involve mental time traveling and reexperiencing the past is assumed to be positively related to the retrieval of specific episodes, according to the notion of episodic memory (Tulving, 1985, 1993; Wheeler et al., 1997) and Brewer's (1996) notion of recollective memories. Second, specific events are most likely to be preserved in memory if they are schema deviant (Schank, 1982) and, thus, unusual. To examine this assumption, a series of two-way ANOVAs were conducted for each of the variables in Table 3 (except specific episodes). Each analysis had two repeated measure factors with two levels (mean ratings of the variable concerned for involuntary vs. word-cued memories $\times$ specific vs. nonspecific memories). Table 4 shows that a main effect was found for specific versus nonspecific on unusualness, event age, vividness, remember/know judgment, rehearsal, importance, and emotion. Involuntary versus word cued showed a main effect on frequencies of mood impact and physical reaction. No interactions were found. A Bonferroni correction for multiple tests showed an adjusted alpha level of $p=.0047$ with 11 independent tests. As Table 4 shows, the main effect for involuntary/word-cued on mood impact thus persists even under such adjustment, and so does the main effect of episodic/nonepisodic on unusualness and event age. The use of adjustments for multiple tests is debated. Although it reduces the risk of Type I errors, adjustment for multiple tests increases the risks of Type II errors, so that truly important differences are classified as insignificant (Perneger, 1998). The latter concern is relevant here, because we have relatively little power in our analyses, due to the fact that they are 
Table 4

Mean Scores for Specific Versus Nonspecific Memories Retrieved Involuntarily and by Word Cues

\begin{tabular}{|c|c|c|c|c|c|c|c|c|c|c|c|}
\hline & \multicolumn{4}{|c|}{ Involuntary } & \multicolumn{4}{|c|}{ Word Cued } & \multirow{2}{*}{\multicolumn{3}{|c|}{$\begin{array}{l}\text { ANOVA } \\
{[F(1,18)]}\end{array}$}} \\
\hline & \multicolumn{2}{|c|}{ Specific } & \multicolumn{2}{|c|}{ Nonspecific } & \multicolumn{2}{|c|}{ Specific } & \multicolumn{2}{|c|}{ Nonspecific } & & & \\
\hline & $M$ & $S D$ & $M$ & $S D$ & $M$ & $S D$ & $M$ & $S D$ & Involuntary/Word & Episode/Nonspecific & Interaction \\
\hline Unusualness & 3.60 & 0.52 & 2.41 & 0.71 & 3.39 & 0.50 & 2.15 & 0.57 & 3.82 & $61.42 \dagger \dagger$ & 0.08 \\
\hline Years old & 2.91 & 2.20 & 6.34 & 4.15 & 3.12 & 1.56 & 5.72 & 2.48 & 0.12 & $32.43 \dagger \dagger$ & 0.97 \\
\hline Vividness & 3.22 & 0.47 & 2.88 & 0.64 & 3.20 & 0.68 & 2.90 & 0.88 & 0.00 & $8.38 \dagger$ & 0.07 \\
\hline Remember/know & 0.51 & 0.22 & 0.44 & 0.26 & 0.47 & 0.25 & 0.36 & 0.24 & 1.76 & $4.77 *$ & 0.47 \\
\hline Rehearsal & 2.27 & 0.58 & 2.48 & 0.81 & 2.31 & 0.52 & 2.79 & 0.86 & 1.89 & $7.76^{*}$ & 1.94 \\
\hline Importance & 2.35 & 0.56 & 2.67 & 0.81 & 2.43 & 0.53 & 2.78 & 0.70 & 0.65 & $7.00 *$ & 0.02 \\
\hline Emotion & 0.21 & 0.30 & 0.45 & 0.66 & 0.36 & 0.28 & 0.56 & 0.48 & 2.09 & $4.91 *$ & 0.05 \\
\hline Intensity & 3.25 & 0.49 & 3.07 & 0.50 & 3.23 & 0.58 & 2.95 & 0.54 & 0.51 & 4.14 & 0.40 \\
\hline Mood change $(+/-)$ & 0.27 & 0.80 & 0.11 & 0.40 & 0.13 & 0.15 & 0.17 & 0.23 & 0.23 & 0.52 & 0.88 \\
\hline Mood impact & 0.48 & 0.21 & 0.50 & 0.32 & 0.38 & 0.21 & 0.35 & 0.28 & $12.23 \ddagger$ & 0.03 & 0.74 \\
\hline Physical reaction & 0.32 & 0.19 & 0.35 & 0.30 & 0.24 & 0.16 & 0.24 & 0.23 & $6.08^{*}$ & 0.23 & 0.35 \\
\hline
\end{tabular}

$* p<.05 . \quad \dagger p<.01 . \quad{ }^{\ddagger} p<.005 . \quad \dagger^{\dagger} p<.0001$.

based on means calculated within each of the 19 participants, and not on the individual memories. In addition, the Bonferroni adjustment is based on the assumption that the analyses are independent, which is partly invalid here, since some of the variables were highly correlated. Thus, the adjusted alpha level gives us a very (and maybe too) conservative picture of what the significant effects are. Even under such conditions, the main pattern of results persists. Involuntary memories involve more emotional reliving, irrespective of whether they refer to specific episodes or summarized events, whereas the differences on unusualness (rated retrospectively for the time of the event) between the two types of memories (cf. Table 3) may be due to the higher frequency of specific episodes among the involuntary memories. Thus, the characteristics of the involuntary memories can be summarized as twofold: They access more specific episodes, and they instigate more emotional reliving.

To explore whether the observed characteristics of involuntary memories varied according to whether the cue was external or internal to the rememberer, the mean ratings of externally and internally triggered memories were compared (memories triggered by mixed cues were left out). Only intensity ratings tended to differ for internally versus externally generated memories $[M \mathrm{~s}=3.30$ and 3.08, respectively; $t(18)=1.87, p=.08$ ]. No differences were found for the remaining variables (all $p \mathrm{~s}>$ .2). Another possible factor could be single versus compound cues (Rubin, 1995). According to notions such as transfer-appropriate processing (Roediger, 1990) and encoding specificity (Tulving \& Thomson, 1973), successful retrieval is contingent on the size of the concrete overlap between the retrieval situation and the memory. Because compound cues refer to more cue categories than do single cues, the former might (other things being equal) be more efficient in accessing specific episodes and reinstating qualities associated with the event. Since several of the involuntary memories had compound cues, whereas the word-cued memories had only single cues, this might explain the observed differences between the two types of memories. To examine this possibility, the mean ratings of involuntary memories triggered by single cues versus compound cues were compared. A series of $t$ tests showed no differences between the two classes of memories (all $p \mathrm{~s}>$.1)

\section{Discussion}

Study 1 showed that involuntary retrieval, more frequently than word-cued memories, accesses memories of specific episodes and involves more mood impact and bodily reaction to the remembered events. There are at least two possible interpretations of these findings. One is that involuntary retrieval is especially efficient in activating memories of specific episodes, as has been suggested by Moscovitch (1994) and Berntsen (1998), and more often than voluntary memories, instigates an emotional and/or bodily response, consistent with some emotion theories (e.g., LeDoux, 1996). In another possible interpretation, the present findings are due to differences between verbal and perceptual cues, rather than to the distinction between involuntary and voluntary memory per se. Since any specific situation includes a seemingly endless amount of perceptual stimuli, and not necessarily any verbal stimuli, the processing of perceptual cues may provide a greater overlap with the processing of episodes at encoding and, thus, be more efficient at activating episodic memories, as compared with verbal cues, according to the notion of transfer-appropriate processing (e.g., Roediger, 1990). A similar assumption can be derived from Tulving's (1985) synergistic ecphory model of retrieval.

Very few studies have compared the phenomenology of autobiographical memories cued by perceptual versus verbal cues. And those that have have tended to focus on odor cues. Rubin, Groth, and Goldsmith (1984) compared memories cued by words, smells, and pictures. They found that memories cued by smells were rated as less thought and talked about than memories cued by words and pictures. Chu and Downes (2000) found that autobiographical memories cued by odors referred to more remote events than did memories cued by verbal labels of smells. 
Using a double-cuing methodology, Chu and Downes (2002) found that memories cued by smells were more vivid and detailed than memories cued by verbal labels and photographs of the sources of the odors. Herz and Schooler (2002) found that odor cues yielded more emotional memories than did verbal and visual cues. In none of these studies were participants asked whether the memories referred to specific episodes or to summarized events. To the best of our knowledge, no previous studies have examined the phenomenology, as well as the specific versus nonspecific nature, of verbally versus perceptually cued autobiographical memories. Study 2 was conducted to provide evidence relevant to this question.

\section{STUDY 2}

This study made use of two different methods for prompting autobiographical memories. Both methods involved voluntary (as opposed to involuntary) retrieval and both derived from the work of Francis Galton (1907). One was the cue word method, which was also used in Study 1 and which has been widely used in research of autobiographical memories after being reintroduced by Crovitz and Schiffman (1974). The other method that we made use of here had not been used since Galton. It may be coined the memory walk method. It consists of retrieving memories to environmental cues that the person actively seeks out while walking around in a well-known environment. Galton invented this method as a precursor for the cue word method. He summarized his selfinstructions as follows: "I walked leisurely along Pall Mall, a distance of 450 yards, during which time I scrutinised with attention every successive object that caught my eyes, and I allowed my attention to rest on it until one or two thoughts had arisen through direct association with that object; then I took a very brief mental note of them and passed on to the next object. I never allowed my mind to ramble" (p. 134). After having taken this walk repeatedly, Galton turned to the more convenient cue word method, which he could accomplish sitting at his desk. In addition to convenience, the cue word method had (and has) the potential for more controlled and systematically varied cuing conditions. However, in the present context, the memory walk is an appropriate method for studying memories that are voluntarily retrieved but, on dimensions related to cuing, comparable to the involuntary memories reported in Study 1. A revised version of Galton's memory walk method was therefore used here to sample voluntary autobiographical memories, retrieved in response to environmental cues that the person actively sought out while moving around in a well-known environment. If the findings in Study 1 were due to differences between verbal and environmental cues (rather than differences between voluntary and involuntary retrieval), we should expect, in the present study, to find similar differences between word-cued memories and memories retrieved in response to cues from the perceptual environment.

\section{Method}

\section{Participants}

One hundred eleven undergraduate psychology majors at the University of Aarhus participated as part of a teaching course (87 females, 24 males; mean age, 26.04 years; range, 21-44).

\section{Design and Procedure}

The participants were randomly assigned to two groups. One group $(n=47)$ recorded 15 memories in response to environmental cues during a memory walk; the other group $(n=64)$ recorded 15 memories in response to word cues. The tasks were self-paced but had to be accomplished within $45 \mathrm{~min}$.

Memory walk task. The participants were told that they were supposed to go for a self-chosen walk around the psychology department. On this walk, they had to record 15 different autobiographical memories and fill in a short questionnaire for each. Between each memory, they had to walk and count 30 steps. When they had walked the 30 steps, they should stop and retrieve a memory in association to a self-chosen cue in their immediate surroundings at this specific location. Possible cues were exemplified in a way that included a wide range of different entities and sensory modalities, such as concrete objects, sounds, body movements, smells, the sight of another person, and the clothes they were wearing themselves. The purpose of counting to 30 and only then stopping and recording was to ensure that recorded memories were retrieved voluntarily, not involuntarily. By separating each of the 15 memories by 30 steps, the participants walked a distance that roughly corresponded to the length of Galton's walk (450 yards).

The participants were instructed to ignore memories that possibly came unbidden. If a participant was unable to record a memory at a specific stop on the walk, he or she could leave the corresponding questionnaire blank, count 30 more steps, and try again at a different stop. The participants were instructed not to talk to other participants on the walk (and to turn off their cell phones). They had to return to the starting point after $45 \mathrm{~min}$, even if they had not recorded all 15 memories.

The psychology department was chosen because it was a wellknown everyday environment to all the participants, in the sense that they had taken part in many social and educational activities at this location prior to the study. Unlike North American undergraduates, undergraduate psychology majors in Denmark take all their courses in psychology and, thus, spend a lot of time at the department, for which reason many features at this place should be able to trigger their memories. This claim is supported by the fact that several of the involuntary memories reported in Study 1 (as well as in earlier diary studies involving Danish psychology students) occurred at this location.

Cue word task. The participants were asked to record 15 different autobiographical memories in response to 15 cue words. The cue words were a subset of the cue words that were used in Study 1. They were selected so that they referred to phenomena that were easily associated to the psychology department. The 15 cue words were (in English translation) book, teacher, party, school, watch, friend, sport, shirt, homework, letter, waiting, flowers, bicycling, window, and telephone. This task was also self-paced and had to be accomplished within $45 \mathrm{~min}$, as in the memory walk condition. Between each memory, the participants had to silently count to 30 and only then turn to a new cue word in the booklet.

Instructions and questionnaire. Both verbal and written instructions were given. The verbal instructions were given in class, before the participants began recording. The written instructions were printed on the first page of the booklets that were used for recording the memories. The distinction between summarized events and specific episodes (Barsalou, 1988) was carefully described and exemplified in the same way as in Study 1. Again, the participants were explicitly allowed to record both types of memories. The questionnaires included the same questions as those answered in both 
the voluntary and the involuntary conditions in Study 1 (see Appendix A), with the following exceptions: Question 18 was left out, because some of the participants in Study 1 had expressed difficulties related to answering this question during the interview that followed recording. A question on how often the person had talked about the memory was added. This question was rated on a 5-point scale ranging from never to very often. In the memory walk condition, the participants were asked to indicate the memory cue and the modality(ies) through which they had perceived the cue. Five possibilities were offered (vision, audition, taste, olfaction, and tactile), and more than one modality could be checked.

\section{Results}

Both tasks were easily accomplished. The memory walk method appeared slightly more time demanding than the word cue technique, since slightly more of the 15 memory questionnaires were left unanswered. Mean proportions answered in the two conditions were .92 and .96 , respectively $[t(109)=2.57, p<.05]$. A total number of 646 memory-walk-cued memories were recorded. Cue and cue modality was not indicated in three cases. Visual cues were reported in $87 \%$, auditory cues in $18 \%$, olfactory cues in $15 \%$, tactile cues in $10 \%$, and gustatory cues in $1 \%$ of the cases. In $77 \%$ of the cases, only one modality was mentioned, whereas two or more were mentioned in $23 \%$ of the cases. In short, cues were predominantly visual, but all sensory modalities contributed, sometimes in combination, consistent with findings on sensory modalities in involuntary memories (Berntsen, 1999).

The study involved multiple observations from each participant. This problem is dealt with in the same way as in Study 1. Table 5 presents the main findings. Only event age differed between the two types of memories. This is most easily explained as a bias in the memory walk condition toward memories related to the psychology department and, thereby, to the participants' lives as psychology students - that is, a bias toward memories less than 3 years old.

To explore whether, in the present study, the distinction between specific and nonspecific memories also was associated with different phenomenological quali-
Table 5

Mean Scores of Memories Cued by Environment and by Words

\begin{tabular}{|c|c|c|c|c|c|}
\hline & \multicolumn{2}{|c|}{ Environment } & \multicolumn{2}{|c|}{ Words } & \multirow[b]{2}{*}{$t(109)$} \\
\hline & $M$ & $S D$ & $M$ & $S D$ & \\
\hline Years old & 4.74 & 3.61 & 6.97 & 4.11 & $2.98 \dagger$ \\
\hline Vividness & 3.63 & 0.53 & 3.77 & 0.44 & 1.60 \\
\hline Specific episodes & 0.65 & 0.19 & 0.61 & 0.17 & 1.34 \\
\hline Thought & 2.69 & 0.52 & 2.80 & 0.47 & 1.12 \\
\hline Importance & 2.54 & 0.52 & 2.65 & 0.53 & 1.07 \\
\hline Intensity & 2.96 & 0.50 & 3.07 & 0.57 & 1.05 \\
\hline Unusualness & 2.76 & 0.46 & 2.87 & 0.61 & 1.04 \\
\hline Physical reaction & 0.29 & 0.19 & 0.32 & 0.22 & 0.75 \\
\hline Mood change $(+/-)$ & 0.22 & 0.21 & 0.19 & 0.23 & 0.71 \\
\hline Emotion & 0.35 & 0.37 & 0.31 & 0.35 & 0.66 \\
\hline Mood impact & 0.49 & 0.20 & 0.51 & 0.22 & 0.51 \\
\hline Talked & 2.41 & 0.56 & 2.37 & 0.51 & 0.41 \\
\hline
\end{tabular}

$\dagger p<.01$.

ties and whether this interacted with the cuing conditions, a series of two ways ANOVAs were conducted for each of the variables in Table 5 (except specific episodes). Each analysis had environmental versus verbal cuing as a between-subjects variable and specific versus nonspecific as a repeated measures factor with two levels. Table 6 shows that a main effect was found for specific versus nonspecific on a number of variables. As in Study 1, as compared with nonspecific memories, memories of specific episodes referred to more unusual, intense, and recent events and were recalled with more vividness. In addition, they were associated with more physical reaction and more mood influence, independently of cuing conditions. As was expected, the distinction between environmental and verbal cues showed only a main effect of event age. This main effect, as well as the interaction, of unusualness disappeared when a Bonferroni adjustment for multiple tests was conducted. According to such adjustment, $p$ levels should be less than .005 .

\section{GENERAL DISCUSSION}

Taken together, the two studies show systematic differences between involuntary and voluntary autobiographical

Table 6

Mean Scores for Specific Versus Nonspecific Memories Retrieved via Environmental and Verbal Cues

\begin{tabular}{|c|c|c|c|c|c|c|c|c|c|c|c|}
\hline & \multicolumn{4}{|c|}{ Environmental } & \multicolumn{4}{|c|}{ Verbal } & \multirow{2}{*}{\multicolumn{3}{|c|}{$\begin{array}{c}\text { ANOVA } \\
{[F(1,106)]}\end{array}$}} \\
\hline & \multicolumn{2}{|c|}{ Specific } & \multicolumn{2}{|c|}{ Nonspecific } & \multicolumn{2}{|c|}{ Specific } & \multicolumn{2}{|c|}{ Nonspecific } & & & \\
\hline & $M$ & $S D$ & $M$ & $S D$ & $M$ & $S D$ & $M$ & $S D$ & Environment/Word & Episode/Nonspecific & Interaction \\
\hline Unusualness & 3.18 & 0.60 & 1.93 & 0.61 & 3.52 & 0.72 & 1.92 & 0.68 & 2.65 & $332.22 \dagger \dagger$ & $5.09 *$ \\
\hline Intensity & 3.16 & 0.60 & 2.51 & 0.79 & 3.34 & 0.62 & 2.64 & 0.77 & 1.97 & $71.98 \dagger \dagger$ & 0.14 \\
\hline Vividness & 3.80 & 0.59 & 3.33 & 0.71 & 3.93 & 0.47 & 3.48 & 0.68 & 2.15 & $43.04 \dagger \dagger$ & 0.01 \\
\hline Years old & 4.06 & 3.56 & 5.52 & 4.82 & 5.66 & 4.03 & 8.48 & 4.97 & $8.52 \dagger$ & $34.56+\dagger$ & 3.34 \\
\hline Physical reaction & 0.33 & 0.24 & 0.24 & 0.25 & 0.38 & 0.26 & 0.21 & 0.23 & 0.01 & $24.89+\dagger$ & 2.14 \\
\hline Mood impact & 0.52 & 0.25 & 0.47 & 0.28 & 0.55 & 0.26 & 0.41 & 0.32 & 0.09 & $9.11 * *$ & 1.92 \\
\hline Talked & 2.35 & 0.62 & 2.38 & 0.90 & 2.40 & 0.59 & 2.39 & 0.69 & 0.06 & 0.01 & 0.05 \\
\hline Thought & 2.66 & 0.62 & 2.68 & 0.79 & 2.79 & 0.57 & 2.84 & 0.65 & 2.12 & 0.17 & 0.05 \\
\hline Importance & 2.48 & 0.64 & 2.58 & 0.89 & 2.62 & 0.65 & 2.70 & 0.77 & 1.29 & 0.84 & 0.01 \\
\hline Emotion & 0.34 & 0.48 & 0.41 & 0.53 & 0.26 & 0.54 & 0.39 & 0.54 & 0.46 & 1.95 & 0.15 \\
\hline Mood change $(+/-)$ & 0.25 & 0.27 & 0.22 & 0.37 & 0.14 & 0.29 & 0.21 & 0.32 & 1.58 & 0.25 & 1.23 \\
\hline
\end{tabular}

$* p<.05 . \quad \dagger p<.01 . \quad * * p<.001 . \quad \dagger p<.0001$. 
memories, on the one hand, and between specific and nonspecific autobiographical memories, on the other. Study 1 showed that involuntary memories referred more frequently to specific episodes and involved more physical reaction and mood impact, as compared with voluntary memories retrieved in response to word cues. We also found that the involuntary memories were rated as referring to more unusual and less positive events. Further analyses showed that the differences on emotion and unusualness (both rated for the time of the event) could be explained as deriving from the higher frequency of specific episodes among the involuntary memories, whereas physical reaction and mood impact at retrieval were unrelated to this distinction. None of the differences between involuntary and voluntary memories appeared related to whether cues were single versus compound or internal versus external. The participants in Study $1 \mathrm{had}$ to always record a voluntary memory immediately after recording an involuntary memory in order to ensure that the word-cued memories were recorded in the same context as the involuntary memories. Possible carryover effects might have rendered the word-cued memories more similar to the involuntary memories and, thereby, reduced the observable differences between the two memory classes. Consistent with previous studies, the retrieval of involuntary memories was highly cue dependent, and the cues were most frequently perceptual features of the environment, rather than internal thoughts.

Study 2 showed that autobiographical memories retrieved voluntarily to self-chosen environmental cues during a memory walk procedure differed from wordcued memories only with respect to their age. Thus, the observed differences between involuntary and voluntary memories in Study 1 could not be explained in terms of a distinction between verbal and environmental cues.

As compared with nonspecific memories, memories of specific episodes again referred to more recent and unusual situations and were associated with more vivid recollection. This effect was independent of whether cues were verbal or perceptual. Wheeler et al. (1997) treated autonoetic awareness (or "time traveling") and reference to specific events as separate, but related, dimensions. The present work confirmed this correlation, since it showed that memories of specific episodes are associated with more reliving than are autobiographical memories with no distinct temporal reference.

The finding that involuntary memories instigate more physical reaction and emotional impact is consistent with LeDoux's (1996) assumption that reactivations of earlier emotional states to a large extent depend on nonvolitional associative processes (for related views, see Lang, 1995; Leventhal \& Scherer, 1987). The finding that involuntary memories more frequently access specific events can be explained in several ways. First, it can be seen to support Moscovitch's (1994, 1995a, 1995b) theory of a distinct memory module for the encoding and associative reactivation of traces of specific episodes. Second, it may be explained in terms of a revised version of the principle of transfer-appropriate processing (Roediger, 1990). Since most episodes in daily life are likely to be encoded incidentally - that is, with no conscious effort directed at remembering the situation concernedone might speculate that specific memories would also most easily be retrieved incidentally, because incidental retrieval would provide the best overlap with the cognitive operations involved in encoding. This explanation agrees with Tulving's (1976) observation that memory performance varies as a function of how well encoding instructions match the retrieval task. Third, in the 1980s, Morton and his colleagues proposed that memories were stored as discrete records, each attached to an access key - or heading - through which the memory was activated (Morton, Hammersley, \& Bekerian, 1985). The access key had no propositional relationship with the content of the memory but was assumed to include "literal representations of the nominal event, including environmental features surrounding the event, and external states existing at the time an event is experienced" (p. 7). According to this view, efficient cues for specific events might often not be generated via a top-down search process. Instead, episodes may spontaneously come to mind in association to features in the environment or thoughts that accidentally provide an overlap with the access key of the memory (Morton, 1990; see also Berntsen, 1998). Fourth, Mandler (1994) assumed that involuntary conscious memories depend on spreading activation in memory networks, optimal in a relaxed state of awarenessthat is, when attention is unfocused. According to this view, the presence of intentional memory descriptions in the voluntary condition in terms of the cue words might sometimes have blocked access to specific events, because the presence of this description and the demand to retrieve something in response to it may have constrained underlying spreading activation processes. Furthermore, according to Mandler, a relaxed state of awareness enhances the availability of relevant memory cues by increasing marginal and subliminal perceptions (see also Kvavilashvili \& Mandler, 2004).

Clearly, these explanations are not mutually exclusive but can be regarded as more or less overlapping. They all appear to accept the idea that some traces of specific episodes are maintained, at least rudimentarily, in longterm memory and that optimal conditions for their reactivation are situations with specific associative links to the memory content and the encoding context (Tulving \& Thomson, 1973). It seems more difficult, on the other hand, to account for the present findings in terms of a topdown constructivist retrieval model of autobiographical memory, because it is complicated to explain how perceptually detailed particulars are constructed from abstract knowledge, and even more so when no goal-directed search is involved. Even in the most well-developed constructivist theory of autobiographical memory (Conway \& Pleydell-Pearce, 2000), a special bottom-up device, called direct retrieval, is included to account for involuntary memories of specific events. Direct retrieval is de- 
fined as "memory formed outside of awareness and outside retrieval mode" (see Haque \& Conway, 2001, p. 531).

It could be argued that because no memory request preceded the involuntary autobiographical memories, they had to be more interesting and distinctive to be noticed in the flow of everyday thoughts than the voluntary autobiographical memories and that this may account for the observed differences between the two types of memories. According to this argument, a better comparison might have been between involuntary memories and voluntary memories recalled in everyday cognition, rather than between involuntary memories and memories recalled to cue words supplied by the experimenter. First, if the distinction between experimenter-generated cues versus self-chosen cues were important, we would have expected to see some differences between the memory walk memories (for which the cues were self-generated) and the word-cued memories in Study 2. Second, the present operationalization of voluntary memories corresponds to the way goal-directed retrieval has been studied in experiments since Ebbinghaus (1885/1964). Whether the findings from these as well as our experiments can be generalized to speak of voluntary autobiographical memories that occur in more natural contexts (e.g., in conversations) is a relevant question for future research. So far, we assume they can. It is our impression that in everyday life, voluntary memories of personal events are often recruited to answer specific requests for information. They are, therefore, likely to be more generic and involve less reliving than their involuntary counterparts.

\section{Broader Perspectives}

The relevance of studies of awareness and episodic memory is well recognized in relation to voluntary retrieval of memory. We have shown that the same topics are relevant in relation to involuntary retrieval. This point is not limited to autobiographical memory, we argue, but applies more generally to memory. In the following, we will specify some of the implications of our work for the two areas of research that we mentioned in the beginning - namely, implicit memory and clinical studies on PTSD and depression.

Implicit memory. According to the original definition, implicit memory is shown when performance on a certain task is facilitated by earlier experience (e.g., a previously studied word) in the absence of conscious recollection of this experience (Schacter, 1987). However, as has been pointed out by many scholars, this definition is ambiguous, because it is not clear whether conscious recollection should refer to intentional retrieval or to phenomenological awareness of the study episode (e.g., Kinoshita, 2001; Mace, 2003a, 2003b; Richardson-Klavehn, Gardiner, \& Java, 1994, 1996; Schacter, Bowers, \& Booker, 1989). To clarify this issue, Schacter et al. recommended a distinction in terms of retrieval intentionality, rather than in terms of conscious awareness, primarily because the latter criterion seems harder to control. According to the retrieval intentional- ity criterion, priming effects in studies with nonamnestic participants can derive from both involuntary unconscious and involuntary conscious memories of items on the studied list. To the extent that the participants actually remember the occurrence of these items on the list, the involuntary conscious memories can be classified as episodic (e.g., Tulving, 2002). Thus, Schacter et al.'s reinterpretation of the implicit/explicit memory distinction leaves a possible role for involuntary conscious memories in studies of implicit memory. Whether or not involuntary conscious memories can enhance priming is nevertheless debated (e.g., Jacoby, 1998; Kinoshita, 2001; Mace, 2003a, 2003b; Richardson-Klavehn et al., 1994, 1996), and only a few studies have been conducted to measure the possible effects of involuntary conscious memories in studies of implicit memory (Mace, 2003a, 2003b; Richardson-Klavehn \& Gardner, 1996; RichardsonKlavehn et al., 1994, 1996).

The present work supports the validity of separating retrieval intentionality and phenomenological awareness (and thereby allowing a possible role for unintended conscious memories). Instead of a positive correlation between retrieval intentionality and phenomenological awareness, we have shown the opposite pattern: Autobiographical memories coming to mind with no retrieval intention are associated with more autonoetic awareness than are memories retrieved voluntarily. To the extent that our findings can be generalized to speak for laboratory studies on implicit memory, they can be seen to agree with Kinoshita's (2001) account on how involuntary conscious memories may enhance priming. On the basis of Moscovitch's (1994, 1995a, 1995b) framework of memory, she argued that a word fragment or stem may work as a memory cue and, via an ecphory process, activate the studied item and bring this item into the focus of attention before alternative words. The outcome is an enhanced priming effect based on involuntary conscious memories. Consistent with this account, the present findings show that involuntary conscious memories are typically activated by an informational overlap with the encoding situation, deal predominantly with specific episodes (analogous to separately studied items on a list), and come with enough conscious awareness to interrupt ongoing mental tasks and focus attention on the content of the memory.

Clinical studies. The present work is relevant in relation to PTSD and depression. Brewin, Dalgleish, and Joseph (1996) have proposed a dual-representation theory of PTSD, according to which parts of the trauma are accessible for deliberate conscious retrieval (verbally accessible memories), whereas other parts can be activated only involuntarily in response to concrete situational cues (situationally accessible memories). Verbally accessible memories are partly reconstructed versions of the original trauma, involving relatively little reliving of original emotion and sensory details, as compared with situationally accessible memories, involving emotionally powerful flashbacks of the trauma (see Holmes, Brewin, \& Hennessy, 2004, for some evidence in sup- 
port of this separation; see Ehlers \& Clark, 2000, for a similar distinction between automatic and intentional memory processes in relation to traumas). An important implication of our findings is that this difference between the phenomenology of voluntary and involuntary memories is not specific to memories for traumas but applies generally to autobiographical memories. Thus, involuntary memories of traumas are not special because they involve more emotional reliving than their voluntary counterparts. This is a characteristic of involuntary autobiographical memories in general.

In a series of studies, Williams and his colleagues have shown that depressed people, to a greater extent than the nondepressed, erroneously respond with overgeneral memories when requested to recall memories for specific autobiographical events (see Williams, 1996, for a review). Similar findings have been obtained in relation to PTSD (see McNally, 2003, for a review). Future research should examine whether a dissociation between involuntary and voluntary autobiographical memories with respect to specificity can be found also for persons with depression and PTSD, so that lack of specificity is less pronounced for depressed and traumatized people's involuntary autobiographical memories, as compared with their voluntary autobiographical memories. If so, this may have implications for how overgeneral memories in depression and PTSD are to be explained. For example, according to one explanation, overgeneral memories in depression are due to a defensive retrieval style developed in childhood to avoid recalling specific memories of negative events (Williams, 1996). Alternatively, overgeneral memories may reflect a lack of ability to initiate effortful cognitive processing in depression (Hertel $\&$ Hardin, 1990). According to the latter explanation, the bias toward retrieving overgeneral memories might be less pronounced in involuntary autobiographical memories, because such memories, by definition, require no controlled initiation of conscious retrieval.

In sum, the relevance of involuntary conscious memories is not limited to autobiographical memory or to work done in naturalistic settings. As was pointed out in the introduction, few laboratory studies have been done on involuntary conscious memories. However, nothing should prevent more being conducted in the future. As has been illustrated by earlier work, methodological obstacles in this area can be overcome. For example, the technique developed by Horowitz (1975) to study intrusive memories of stressful films can be revised and used to study involuntary memories with other experimental designs (e.g., Holmes et al., 2004; Kvavilashvili \& Schlagman, 2003). What the present work on involuntary autobiographical memories shows is that the understanding we get of the content and workings of conscious memory changes with the retrieval task. Involuntary conscious memory is a way of sampling memories that, by definition, is uninfluenced by search descriptions generated in a top-down fashion but, on the other hand, appears to be highly dependent on available environmental cues. In contrast, retrieving memories voluntarily in response to specific requests may often lead to memories that are biased and constructed to meet the request. Both voluntary and involuntary conscious memories are indispensable in everyday life. A valid understanding of memory therefore requires that we sample memories in both ways and continue to clarify their differences and the possible mechanisms behind them.

\section{REFERENCES}

American Psychiatric Association (1994). Diagnostic and statistic manual of mental disorders (4th ed.). Washington, DC: Author.

BarClay, C. R. (1993). Remembering ourselves. In G. M. Davies \& R. H. Logie (Eds.), Memory in everyday life (pp. 285-309). Amsterdam: North-Holland.

BARSALOU, L. W. (1988). The content and organization of autobiographical memories. In U. Neisser \& E. Winograd (Eds.), Remembering reconsidered: Ecological and traditional approaches to the study of memory (pp. 193-243). New York: Cambridge University Press.

BERNTSEN, D. (1996). Involuntary autobiographical memories. Applied Cognitive Psychology, 10, 435-454.

BERNTSEN, D. (1998). Voluntary and involuntary access to autobiographical memory. Memory, 6, 113-141.

BERNTSEN, D. (1999). Moments of recollection. A study of involuntary autobiographical memories. Unpublished doctoral dissertation, Aarhus Universitet.

BERnTSEn, D. (2001). Involuntary memories of emotional events: Do memories of traumas and extremely happy events differ? Applied Cognitive Psychology, 15, 135-158.

BERNTSEN, D. (2002). Tunnel memories for autobiographical events: Central details are remembered more frequently from shocking than from happy experiences. Memory \& Cognition, 30, 1010-1020.

Berntsen, D., \& Rubin, D. C. (2002). Emotionally charged autobiographical memories across the life span: The recall of happy, sad, traumatic, and involuntary memories. Psychology \& Aging, 17, 636652.

BREWER, W. F. (1996). What is recollective memory? In D. C. Rubin (Ed.), Remembering our past: Studies in autobiographical memory (pp. 19-66). Cambridge: Cambridge University Press.

Brewin, C. R., Christodoulides, J., \& Hutchinson, G. (1996). Intrusive thoughts and intrusive memories in a nonclinical sample. Cognition \& Emotion, 10, 107-112.

BREWIN, C. R., DALGLeISH, T., \& JosePh, S. (1996). A dual representation theory of posttraumatic stress disorder. Psychological Review, 103, 670-686.

CHU, S., \& Downes, J. J. (2000). Long live Proust: The odour-cued autobiographical memory bump. Cognition, 75, 41-50.

Chu, S., \& Downes, J. J. (2002). Proust nose best: Odors are better cues of autobiographical memory. Memory \& Cognition, 30, 511-518.

CoHEn, J., \& CoHEN, P. (1983). Applied multiple regression/correlation analysis for the behavioral sciences (2nd ed.). Hillsdale, NJ: Erlbaum.

ConWAY, M. A. (1992). A structural model of autobiographical memory. In M. A. Conway, D. C. Rubin, H. Spinnler, \& W. A. Wagenaar (Eds.), Theoretical perspectives on autobiographical memory (pp. 167-194). Dordrecht: Kluwer.

Conway, M. A., \& Pleydell-Pearce, C. W. (2000). The construction of autobiographical memory in the self-memory system. Psychological Review, 107, 261-288.

Crovitz, H. F., \& Schiffman, H. (1974). Frequency of episodic memories as a function of their age. Bulletin of the Psychonomic Society, 4, 517-518.

Ebbinghaus, H. (1964). Memory: A contribution to experimental psychology. New York: Dover. (Original work published 1885)

Ehlers, A., \& ClaRK, D. M. (2000). A cognitive model of posttraumatic stress disorder. Behavior Research \& Therapy, 38, 319-345.

Ericsson, K. A., \& Simon, H. A. (1980). Verbal reports as data. Psychological Review, 87, 215-251.

FoDOR, J. A. (1983). The modularity of mind. Cambridge, MA: MIT Press. GaLton, F. (1907). Inquiries into human faculty and its development. London: Dent. 
Haque, S., \& Conway, M. A. (2001). Sampling the process of autobiographical memory construction. European Journal of Cognitive Psychology, 13, 529-547.

Harber, K. D., \& Pennebaker, J. W. (1992). Overcoming traumatic memories. In S.-Å. Christianson (Ed.), The handbook of emotion and memory: Research and theory (pp. 359-387). Hillsdale, NJ: Erlbaum.

Hertel, P. T., \& Hardin, T. S. (1990). Remembering with and without awareness in a depressed mood: Evidence of deficits in initiative. Journal of Experimental Psychology: General, 119, 45-59.

HERZ, R. S., \& SCHOOLER, J. W. (2002). A naturalistic study of autobiographical memories evoked by olfactory and visual cues: Testing the Proustian hypothesis. American Journal of Psychology, 115, 21-32.

Holmes, E. A., Brewin, C. R., \& Hennessy, R. G. (2004). Trauma films, information processing, and intrusive memory development. Journal of Experimental Psychology: General, 133, 3-22.

HorowITZ, M. J. (1975). Intrusive and repetitive thought after experimental stress: A summary. Archives of General Psychiatry, 32, $1457-$ 1463.

JACOBY, L. L. (1998). Invariance in automatic influences on memory: Toward a user's guide for the process-dissociation procedure. Journal of Experimental Psychology: Learning, Memory, \& Cognition, 24, 3-26.

KinOSHITA, S. (2001). The role of involuntary aware memory in the implicit stem and fragment completion task: A selective review. $\underline{P s y-}$ chonomic Bulletin \& Review, 8, 58-69.

KLOS, D. S., \& SingeR, J. L. (1981). Determinants of the adolescent's ongoing thought following simulated parental confrontations. Journal of Personality \& Social Psychology, 41, 975-987.

KVAVILASHVILI, L., \& MANDLER, G. (2004). Out of one's mind: A study of involuntary semantic memories. Cognitive Psychology, 48, 47-94.

Kvavilashvili, L., \& Schlagman, S. (2003, July). Eliciting involuntary autobiographical memories in the laboratory: Developing a new method of investigation. Paper presented at the Conference of Society for Applied Research in Memory and Cognition (SARMAC), University of Aberdeen.

LANG, P. J. (1995). The emotion probe: Studies of motivation and attention. American Psychologist, 50, 372-385.

LARSEN, S. F. (1998). What is it like to remember? On phenomenal qualities of memory. In C. P. Thompson, D. J. Herrmann, D. Bruce, J. D. Read, D. G. Payne, \& M. P. Toglia (Eds.), Autobiographical memory: Theoretical and applied perspectives (pp. 163-190). Mahwah, NJ: Erlbaum.

Larsen, S. F., \& Seilman, U. (1988). Personal remindings while reading literature. Text, 8, 411-429.

LeDoux, J. E. (1996). The emotional brain: The mysterious underpinnings of emotional life. New York: Simon \& Schuster.

Leventhal, H., \& Scherer, K. R. (1987). The relationship of emotion to cognition: A functional approach to a semantic controversy. $\underline{C o g}$ nition \& Emotion, 1, 3-28.

MACE, J. H. (2003a). Involuntary aware memory enhances priming on a conceptual implicit memory task. American Journal of Psychology, 116, 281-290.

MACE, J. H. (2003b). Study-test awareness can enhance priming on an implicit memory task: Evidence from a word completion task. American Journal of Psychology, 116, 257-279.

MANDLER, G. (1989). Memory: Conscious and unconscious. In P. R. Solomon, G. R. Goethals, C. M. Kelly, \& B. R. Stephens (Eds.), Memory: Interdisciplinary approaches (pp. 84-106). New York: Springer-Verlag.

MANDLER, G. (1994). Hypermnesia, incubation, and mind-popping: On remembering without really trying. In C. Umiltà \& M. Moscovitch (Eds.), Attention and performance: Conscious and unconscious information processing (pp. 3-33). Cambridge, MA: MIT Press.

MasLow, A. H. (1959). Cognition of being in the peak experience. Journal of Genetic Psychology, 94, 43-66.

MCNally, R. J. (2003). Remembering trauma. Cambridge, MA: Harvard University Press.

McNally, R. J., Lasko, N. B., Macklin, M. L., \& Pitman, R. K. (1995). Autobiographical memory disturbance in combat-related posttraumatic stress disorder. Behavior Research \& Therapy, 33, 619-630.

Miller, G. A. (1974). Psychology: The science of mental life. London: Penguin. (Original work published 1962)
Morton, J. (1990). The development of event memory. The Psychologist, 1, 3-10.

Morton, J., Hammersley, R. H., \& Bekerian, D. A. (1985). Headed records: A model for memory and its failures. Cognition, 20, 1-23.

Moscovitch, M. (1994). Memory and working with memory: Evaluation of a component process model and comparisons with other models. In D. L. Schacter \& E. Tulving (Eds.), Memory systems (pp. 269309). Ca mbridge, MA: MIT Press.

Moscovitch, M. (1995a). Models of consciousness and memory. In M. S. Gazzaniga (Ed.), The cognitive neurosciences (pp. 1341-1354). Cambridge, MA: MIT Press.

Moscovitch, M. (1995b). Recovered consciousness: A hypothesis concerning modularity and episodic memory. Journal of Clinical \& Experimental Neuropsychology, 17, 276-290.

NeISSER, U. (1982a). John Dean's memory: A case study. In U. Neisser (Ed.), Memory observed: Remembering in natural contexts (pp. 139159). San Francisco: Freeman.

NeISSER, U. (1982b). Memory: What are the important questions? In U. Neisser (Ed.), Memory observed: Remembering in natural contexts (pp. 3-19). San Francisco: Freeman.

Nelson, K. (1993). Explaining the emergence of autobiographical memory in early childhood. In A. C. Collins, S. E. Gathercole, M. A. Conway, \& P. E. M. Morris (Eds.), Theories of memory (pp. 355387). Hove, U.K.: Erlbaum.

Nisbett, R. E., \& Wilson, T. D. (1977). Telling more than we can know: Verbal reports on mental processes. Psychological Review, $\mathbf{8 4}_{2}$ 231-259.

PERNEGER, T. V. (1998). What's wrong with Bonferroni adjustments. British Medical Journal, 316, 1236-1238.

Proust, M. (1932-1938). På sporet efter den tabte tid [À la recherce du temps perdu/Remembrance of Things Past]. Copenhagen: Martins Forlag.

Reynolds, M., \& BRewin, C. R. (1999). Intrusive memories in depression and posttraumatic stress disorder. Behaviour Research \& Therapy, 37, 201-215.

RiCHARDSON-KLAVEHN, A., \& GARDINER, J. M. (1996). Cross-modality priming in stem completion reflects conscious memory, but not voluntary memory. Psychonomic Bulletin \& Review, 3, 238-244.

Richardson-Klavehn, A., GARDINER, J. M., \& JAVA, R. I. (1994). Involuntary conscious memory and the method of opposition. Memory, 2, 1-29.

Richardson-Klavehn, A., Gardner, J. M., \& Java, R. I. (1996). Memory: Task dissociations, process dissociations and dissociations of consciousness. In G. Underwood (Ed.), Implicit cognition (pp. 85158). Oxford: Oxford University Press.

Roediger, H. L., III (1990). Implicit memory: Retention without remembering. American Psychologist, 45, 1043-1056.

Ross, B. H. (1984). Remindings and their effects in learning a cognitive skill. Cognitive Psychology, 16, 371-416.

Rubin, D. C. (1995). Memory in oral traditions: The cognitive psychology of epic, ballads, and counting-out rhymes. New York: Oxford University Press.

Rubin, D. C., Burt, C. D. B., \& Fifield, S. J. (2003). Experimental manipulations of the phenomenology of memory. Memory \& Cognition, 31, 877-886.

RUBin, D. C., GROTH, E., \& Goldsmith, D. (1984). Olfactory cuing of autobiographical memory. American Journal of Psychology, 97, 493507.

Rubin, D. C., Schrauf, R. W., \& Greenberg, D. L. (2003). Belief and recollection of autobiographical memories. Memory \& Cognition, 31, 887-901.

RugG, M. D., Fletcher, P. C., Frith, C. D., Frackowiak, R. S. J., \& Dolan, R. J. (1997). Brain regions supporting intentional and incidental memory: A PET study. NeuroReport, 8, 1283-1287.

Salaman, E. (1982). A collection of moments. In U. Neisser (Ed.), Memory observed: Remembering in natural contexts (pp. 49-63). San Francisco: Freeman.

SCHACTER, D. L. (1987). Implicit memory: History and current status. Journal of Experimental Psychology: Learning, Memory, \& Cognition, 13, 501-518.

SCHACTER, D. L., BOWERs, J., \& BoOKER, J. (1989). Intention, awareness and implicit memory: The retrieval intentionality criterion. In 
S. Lewandowsky, J. C. Dunn, \& K. Kirsner (Eds.), Implicit memory: Theoretical issues (pp. 47-65). Hillsdale, NJ: Erlbaum.

SCHACTER, D. L., \& BUCKNER, R. L. (1998). On the relations among priming, conscious recollection, and intentional retrieval: Evidence from neuroimaging search. Neurobiology of Learning \& Memory, 70, 284-303.

ScHANK, R. C. (1982). Dynamic memory: A theory of reminding and learning in computers and people. New York: Cambridge University Press.

Slater, M. (1991). Proust, psychoanalysis and involuntary memory. Literature \& Psychology, 37, 1-10.

Stevenson, I., \& CoOK, E. W. (1995). Involuntary memories during severe physical illness or injury. Journal of Nervous \& Mental Disease, $\mathbf{1 8 3}, 452-458$.

ThOMPSON, C. P., Skowronski, J. S., Larsen, S. F., \& Betz, A. L. (1996). Autobiographical memory: Remembering what and remembering when. Hillsdale, NJ: Erlbaum.

Tulving, E. (1976). Ecphoric processes in recall and recognition. In J. Brown (Ed.), Recall and recognition (pp. 37-73). London: Wiley.
Tulving, E. (1985). Memory and consciousness. Canadian Psychology, 26, 1-26.

Tulving, E. (1993). What is episodic memory? Current Directions in Psychological Science, 2, 67-70.

Tulving, E. (2002). Episodic memory: From mind to brain. Annual Review of Psychology, 53, 1-25.

Tulving, E., \& THOMson, D. M. (1973). Encoding specificity and retrieval processes in episodic memory. Psychological Review, 80, 352373.

Wheeler, M. A., Stuss, D. T., \& Tulving, E. (1997). Toward a theory of episodic memory: The frontal lobes and autonoetic consciousness. Psychological Bulletin, 121, 331-354.

Williams, J. M. G. (1996). Depression and the specificity of autobiographical memory. In D. C. Rubin (Ed.), Remembering our past: Studies in autobiographical memory (pp. 244-267). Cambridge: Cambridge University Press.

WRIGHT, D. B. (1998). Modelling clustered data in autobiographical memory research: The multilevel approach. Applied Cognitive Psychology, 12, 339-357.

\section{APPENDIX A \\ Questions Included in the Questionnaire for Each Involuntary Memory}

Keyword phrases and ratings were recorded in the notebook for questions marked by an asterisk. Questions 7 and Questions 10-19 were also answered for the word-cued memory.

1. *Where were you when the memory came to your mind?

2. *What were you doing?

3. *Did you think of something else while you were doing this?

4. *How was your mood? (very poor $-2-1012$ very good)

5. Describe the situation in your own words. (who were present? particular objects? sounds, colors, wording etc.)

6. *Describe the memory.

7. Does this memory refer to a particular episode in your past? (yes/no)

8. Compare the content of the memory with what had taken place in your thoughts and surroundings right before the memory came to your mind. Did anything in your surroundings, or anything in your activity, attention, or what had been on your mind repeat itself in the memory? Check the most salient commonalities. (person(s)/place/sensory experience/object/feeling/life theme/theme/activity/wording/ other/no commonalities)

9. Were the commonality/ies present in your external/physical surroundings or only present in thought? (external/internal/both)

10. *How vivid is the memory? $(1=$ cloudy and imageless; $5=$ as clear and vivid as if it was experienced again)

11. *Did the memory affect your mood? (better/worse/no impact)

12. *Did you react physically in response to the memory - for example, by talking to yourself, smiling, crying, shivering, palpitation, laughing, hitting things, etc.? (yes/no/ if yes, please write how)

13. Have you previously thought about this memory? $(1=$ never; $5=$ very often $)$

14. Does the memory refer to an important or unimportant event in your life? $(1=$ fairly unimportant; $5=$ very important)

15. Was the remembered situation common or unusual to you when it took place? $(1=$ completely ordinary; 5 = completely unusual)

16. *Was the remembered situation emotionally positive or negative when it took place? $(-2=$ very negative; 2 = very positive)

17. *Was the remembered situation emotionally intense or without intensity when it took place? $(1=$ without intensity; 5 = very intense)

18. *Do you remember your emotional state (by reexperiencing it) or do you simply know what your emotions were like when the event took place - for example, by making inferences based on the content? $(1$ = I remember (reexperience) my emotional state; 2 = I know (infer) how I felt)

19. How old is the memory? 
APPENDIX B

Cue Words Used in Study 1 and Their Distribution Across the Thematic Categories Derived From Berntsen (1996)

\begin{tabular}{lllllll}
\hline Activity & Object & Relationship & Sensory Experience & Theme & Location & Emotion \\
\hline Party & CD & mum & birdsong & divorce & school & happy \\
Working & book & dad & view & sports & cinema & sad \\
Bicycling & watch & friend & salt & chance & farm & panic \\
Waiting & shirt & family & snow & drugs & & \\
Cleaning & poster & teacher & rain & & \\
Homework & flowers & pet & barbecue smell & & \\
Traveling & telephone & & & & \\
Shopping & letter & & & & \\
\hline
\end{tabular}

(Manuscript received December 15, 2002;

revision accepted for publication January 6,2004 .) 